\title{
Candy Elasticity: Halloween Experiments on Public Political Statements
}

\author{
Julian Jamison ${ }^{1}$ and Dean Karlan ${ }^{2}$
}

January 2015

\begin{abstract}
We conducted experiments during trick-or-treating on Halloween in a predominantly liberal neighborhood in the weeks preceding the 2008 and 2012 presidential elections. We decorated one side of a house porch with McCain material in 2008 (Romney material in 2012) and the other side with Obama material. Children were asked to choose a side, with half receiving the same candy on either side and half receiving more candy to go to the McCain/Romney side. This yields a "candy elasticity" of children's political support. Results vary by age: children ages nine and older were two to three times more likely to choose the Republican candidate when offered double candy for voting Republican compared to when offered equal candy, while children ages eight and under were particularly sticky and did not waver in their choice of candidate despite the offer of double candy.
\end{abstract}

JEL codes: C93; D72; D12

Keywords: election field experiment; elasticity and intensity of political preference; child participants

1 Contact email: julison@gmail.com. Author affiliation: Consumer Financial Protection Bureau. The views expressed are those of the authors and do not necessarily reflect those of the Consumer Financial Protection Bureau or the United States.

2 Contact email: dean.karlan@yale.edu. Author affiliation: Yale University. This paper is based on previous drafts circulated under the titles "Candy We Can Believe In: A Halloween Experiment on Trust and Political Symbolism" and "Candy We Still Believe In: Using Halloween to Measure Change in Extensive and Intensive Support for Barack Obama." We thank Yale University for research support. Human Subjects Approval provided by Yale University IRB \# 1210010995 and 0710003195. We gratefully acknowledge the editor Yoram Bauman and three anonymous referees, Treb Allen, Gharad Bryan, Snaebjorn Gunnsteinsson, Melanie Morten, Scott Nelson, Bram Thuysbaert, Jane Bang, Zachary Groff, Sakshi Kumar, Kelsey Larson, Adèle Rossouw, and Martin Sweeney for written contributions and research assistance; Muneeza Alam, Iva Rashkova, and Katie Wilson for assistance running the 2008 field experiment; and Emek Basker, Dan Keniston, and Ryan Knight for insightful suggestions. 
"If you're not a liberal when you're 25, you have no heart. If you're not a conservative by the time you're 35, you have no brain."

- Francois Guisot, French premier and historian $(1787-1874)^{3}$

"I want candy!"

- Every kid, ever.

\section{Introduction}

We exploit the second premise to test the first premise.

We conducted trick-or-treat experiments to learn about political attitudes before the 2008 and 2012 presidential elections. ${ }^{4}$ We set up two tables on the porch of a home for Halloween, one festooned with McCain campaign props in 2008 (Romney in 2012) and the other with Obama props. Children, at the stairs leading up to the porch, were told they could choose which side to go. Half of the children were randomly assigned to be offered twice as much candy for the McCain table (Romney in 2012), and half were offered an equal amount. ${ }^{5,6}$ We can compare the change in the overall support for Obama in 2008 versus 2012 by comparing the proportion that choose Obama (i.e., the external margin), as well as the change in the intensity of the support for President Obama by comparing the elasticity with respect to candy (i.e., the intensive margin). ${ }^{7,8}$

The experimental setup allows us to measure not just what proportion of children who trick-ortreat in this neighborhood support each candidate (as indicated by their choice of table), but also how elastic their support is, or, more precisely, how elastic their desire is to make a public statement of their support. In 2008, 79\% of children chose the Obama table with no incentives, while $71 \%$ of children chose the Obama table when offered double the candy at the McCain table. In 2012, 82\% of children chose the Obama table with no incentive, while $78 \%$ of children chose the Obama table when promised double candy at the Romney table.

Children's responses to the candy incentives varied by age, however. Younger children's preference for Obama was sticky with respect to price, but older children's preference for Obama was elastic. This result was first observed in 2008 and then successfully replicated in the 2012 experiment. We discuss several interpretations in the conclusion, including a differential response to symbolic versus monetary rewards, a parental-contamination story for the younger children, and the simplest possibility: that younger children just didn't understand the task as much and so made the political choice they did understand.

${ }^{3}$ The exact quote: "Not to be a republican at twenty is proof of want of heart; to be one at thirty is proof of want of head." (Shapiro 2006). This quote is often falsely attributed to Winston Churchill.

4 We also replicated results from a 2007 Halloween experiment, in which children who wore the most common costumes exhibited more aversion to ambiguity; see Anagol et al. (2008) for those results. Note that experiments on trick-or-treaters have a history in the psychology literature - see Read and Loewenstein (1995) for an example regarding choice bracketing, albeit with a much smaller sample size.

5 Providing an incentive to go to the Obama table would have been logistically infeasible: since this neighborhood heavily supported Obama, we had to provide an opposing incentive to even length of processing time on each side of the porch.

${ }^{6}$ We also conducted an additional experiment in each year (see notes 7 and 8) in which trick-or-treaters did not get a choice of sides, and were randomly assigned. Those observations are not included in the analysis here.

7 The 2008 experiment contained a decision upon collecting their candy, to accept a clear bag or paper bag with candy. This was part of a second study on trust and comfort with ambiguity. Trick-or-treaters assigned to a side (rather than choosing a side) are omitted from the analysis here. See http://karlan.yale.edu/p/HalloweenPolitics_v4.pdf for results related to the trust component.

8 The 2012 experiment also contained a decision upon collecting their candy, to choose candy or fruit. Again, as with the 2008 experiment, trick-or-treaters assigned to a side (rather than choosing a side) are omitted from the analysis here. See http://karlan.yale.edu/p/Michelle-2012.pdf for results related to the candy or fruit experiment. 


\section{Experimental Design - 2008 Election (Obama and McCain)}

We conducted the experiment on the front porch of a home in the East Rock neighborhood of New Haven, CT. The neighborhood has closely-located homes, and a high proportion of residents pass out candy. It is popular with trick-or-treaters, both from the immediate neighborhood and from neighboring communities. A typical home in this neighborhood receives more than 500 trick-or-treaters each Halloween. We used this large flow of individuals to test several aspects of political choice. ${ }^{9}$

Two tables were set up on the front porch of the home. The right side of the porch was decorated with John McCain election material and the left side of the porch was decorated with Barack Obama election material. In addition, life-size cutouts of each candidate, clearly visible, stood on their respective sides.

Trick-or-treaters were met in front of the porch and told to draw a number from a bowl that assigned them randomly to one of two groups: ${ }^{10}$

1. Equal Candy: Children were asked, "You can get two pieces of candy from the Obama table, or two pieces of candy from the McCain table. Which do you prefer?"

2. Double Candy for Voting Republican: Children were asked, "You can get two pieces of candy from the Obama table, or four pieces of candy from the McCain table. Which do you prefer?"

322 individuals participated in the experiment. If a child was too young to understand the initial choice between the Obama and McCain tables, they did not participate in the experiment and are not included in our analysis (they were, however, still given candy). ${ }^{11}$ We limited the trick-or-treaters included in our analysis to those between and including age four and $15 .^{12}$

The experimental design allows us to calculate the "candy elasticity" of McCain. The sample for this analysis is all children who were assigned to Treatment 1 or Treatment 2 (322 children). In order to avoid potential gender confound, one female and one male experimenter sat behind each candidate's table and alternated speaking. The gender of the experimenter had no effect on any of the treatments.

Although many children arrived in groups, raising issues of social conformity influencing individual decisions and thus creating lack of independence across observations, we strived to interact with the children one-on-one, without interference by others, by separating the queue from the decision area. Specifically, the queue to the porch started about three feet in front of the steps to the porch. We placed several chairs there to block the flow of traffic. We then brought each child one at a time to the steps of the porch, explained their options to them, and then let them go up to the top of the stairs and to one of the sides of the porch. We cannot claim that this method was perfect. We posit that any influence of social conformity would lead to incorrect (underestimated) standard errors, but would less likely create biased estimates. However, if social contagion leads those with minority views (i.e., in this environment, supportive of Republicans) to hide their views and publicly show support for Obama, this would upwardly bias the proportion supporting Obama.

The summary statistics for the sample population are given in Table 1 and brief descriptive

\footnotetext{
9 Because no individual identifying information was recorded about each child, and because no harm (beyond that of the socially acceptable excessive sugar intake) was imposed on the children, this was approved by Yale University's Institutional Review Board without needing explicit signed consent by the parents of each child.

${ }^{10}$ There were actually two more groups for a total of four: half of the trick-or-treaters were assigned to one table or the other for the trust experiment described in footnote 6 . As we are not using these other two treatment groups for any of the analysis, we are describing the study throughout as just having two experimental conditions.

${ }^{11}$ We judged 21 children to be too young to understand the question related to the additional candy bag treatment (see footnote 4), so although they arrived at either the McCain or Obama table, they are omitted from all experimental results (and are not considered part of our sample). Age was not recorded for 25 children, who were omitted from our age group analyses.

${ }^{12}$ We excluded from the analysis six trick-or-treaters three years old or less and 17 trick-or-treaters 15 years old or older.
} 
statistics are given in Table 2.

\section{Results - 2008 Election (Obama and McCain)}

In the "equal candy" treatment, $79 \%$ of children chose the Obama table, reflecting the high level of support for the Democratic Party in New Haven, CT. ${ }^{13}$ When offered twice the amount of candy to go to the McCain table, $71 \%$ of the children still chose the Obama table, though the difference is not statistically significant (Table 1).

Note that the preference for Obama is likely understated, as there was consistently a longer line at the Obama table than at the McCain table. This means that even in the "equal candy" treatment, the "cost" of acquiring candy from the Obama side was slightly higher, as a long line is costly for subjects intent on maximizing their total candy intake for the evening. ${ }^{14}$

Children ages eight and under did not respond to the additional candy incentives approximately $30 \%$ of children chose the McCain table in both treatment groups. Children ages nine and older however, were much more responsive to the candy incentive. The percentage of older children that visited the McCain table increased from $10 \%$ without the incentives to $30 \%$ with the incentives.

In the conclusion, we posit several explanations for this heterogeneity.

\section{Experimental Design - 2012 Election (Obama and Romney)}

We conducted a variant of our 2008 experiment one week before the 2012 presidential election, substituting McCain material with Romney material. The purpose of the replication was to determine whether or not the overall support and the enthusiasm of support for Obama had dwindled since 2008. Trick-or-treaters were met in front of the porch and told to draw a number from a bag that assigned them randomly to one of two groups:

1. Equal Candy: Children were asked, "You can get one piece of candy from the Obama table, or one piece of candy from the Romney table. Which do you prefer?"

2. Double Candy for Voting Republican: Children were asked, "You can get one piece of candy from the Obama table, or two pieces of candy from the Romney table. Which do you prefer?"

The summary statistics for the sample population of 157 people are given in Table 3 and brief descriptive statistics are given in Table 4. The sample size is lower than in 2008 because Hurricane Sandy affected the New Haven community a week before Halloween, and lingering effects adversely affected turnout for trick-or-treating. ${ }^{15}$

\section{Results - 2012 Election (Obama and Romney)}

Our results are largely consistent with the results from 2008, suggesting that support for Obama in this context has not declined since $2008.82 \%$ of children chose Obama in the "equal candy" treatment, while $78 \%$ of children chose Obama when twice as much candy was offered at the Romney table.

As in 2008, for children ages nine and older, the double candy incentive seemed to encourage some Obama supporters to choose Romney. While 17\% of older children chose Romney when offered

\footnotetext{
${ }^{13}$ In the actual 2008 presidential election, $61 \%$ of New Haven County voters voted for Barack Obama and $38 \%$ voted for John McCain (source: http://elections.nytimes.com/2008/results/president/map.html).

${ }^{14}$ Of course the subjects may have desired to spend time with their friends, so a popular table is not inherently costly even if the wait is longer.

15 The immediate neighborhood was not affected seriously by Hurricane Sandy, unless one considers intermittent buffering of streaming Netflix videos during the storm as a serious adverse consequence. Regardless, the mayor of New Haven announced the "suggestion" to delay trick-or-treating by a week, thus creating confusion for some, lower turnout on Halloween, and lower statistical power for this experiment.
} 
equal candy, $31 \%$ of older children chose Romney when offered double candy. For children ages eight or under, the double candy incentive had the opposite effect: $18 \%$ chose Romney when offered equal candy, while $14 \%$ chose Romney when offered more candy.

\section{Conclusion}

While the choice of tables is entirely benign, it appears strikingly inelastic. Despite the strictly symbolic nature of choosing one table over another, most children chose the Obama table even when offered twice as much candy at the McCain/Romney table. Seventy-nine percent of children chose the Obama table with no incentives, while $71 \%$ of children chose the Obama table even when incentivized to choose the McCain table. In 2012, 82\% of children chose the Obama table with no incentives, whereas $78 \%$ of children chose the Obama table when incentivized to go to the Romney table. These results suggest that the level of overall support and the enthusiasm of support for Obama remained roughly the same from 2008 to 2012 .

We observe important heterogeneity: children ages nine and older were much more likely to be swayed by the double candy incentives than children ages eight and under. We posit several possible interpretations: (1) Younger children may have seen the choosing of a table as deeply symbolic of their choice for President, whereas older children may have seen it more as a simple game. ${ }^{16}$ (2) Younger children may have been less capable of processing the tradeoff. Given their confusion, they may have focused on the easier political choice. Although we posit this as a viable explanation, in past Halloween experiments we did not find differential responses by age even when the exercise was more complicated. (3) Children eight and under may perceive this as their chance to state publicly their political preferences and take the process more literally, whereas older children may see this public statement as having less meaning. This may be the case even if younger children are less politically engaged or possess less political knowledge. (4) Younger children were more likely to have their parents nearby, and thus may have been reluctant to change their choice for candy. ${ }^{17}$ The political science and child development literature typically documents the formation of political preference in the mid-teen years (Tedin 1974; Beck and Jennings 1982; R. Murray and Mulvaney 2012), suggesting the heterogeneity by age we find may be a by-product of differential obedience to parental preference and not inelastic versus elastic political preferences.

Several sample selection and experimental interpretation issues are important to note. First, East Rock is an enclave of Yale University and borders lower socioeconomic neighborhoods. In both election years, the proportion of children in the "equal candy" treatments that chose the Obama table was greater than the proportion of New Haven County voters that voted for Barack Obama. Thus even those who support McCain do so knowing they are in the minority in their community, and this could lead to differences in behavior relative to how McCain supporters in more conservative neighborhoods would behave. Second, for some younger children, it was not possible to get them to decide without the parent observing them, or making a suggestion to them. However, on the rare occasions when a pushy parent clearly chose on behalf of the child, we noted this and dropped the data point. Finally, as with any empirical exercise, questions of external validity remain. In particular, it is unclear whether the results of this experiment were particular to the 2008 and 2012 elections, particular to Obama, or particular to some other circumstance surrounding these two experiments.

\footnotetext{
${ }^{16}$ Such a result for young children would not be unprecedented: Murnighan and Saxon (1998) finds that children age eight to nine display a strong sense of fairness in the ultimatum game, even if it entails forgone rewards.

${ }^{17}$ Note that had any parents explicitly influenced the child, the data were not collected. The child merely received candy and we moved on to the next participant. Naturally the mere presence of a parent may influence the child's choices.
} 


\section{References}

Anagol, S., S. Bennett, G. Bryan, T. Davenport, N. Hite, D. Karlan, P. Lagunes, and M. McConnell. 2008. "There's Something about Ambiguity." Yale University Working Paper.

Beck, Paul Allen, and M. Kent Jennings. 1982. "Pathways to Participation." The American Political Science Review 76 (1): 94-108. doi:10.2307/1960445.

Murnighan, J. Keith, and Michael Scott Saxon. 1998. "Ultimatum Bargaining by Children and Adults." Journal of Economic Psychology 19 (4): 415-45. doi:10.1016/S0167-4870(98)00017-8.

Read, Daniel, and George Loewenstein. 1995. "Diversification Bias: Explaining the Discrepancy in Variety Seeking between Combined and Separated Choices." Journal of Experimental Psychology: Applied 1 (1): 34-49. doi:10.1037/1076-898X.1.1.34.

R. Murray, Gregg, and Matthew K. Mulvaney. 2012. "Parenting Styles, Socialization, and the Transmission of Political Ideology and Partisanship.” Politics \& Policy 40 (6): 1106-30. doi:10.1111/j.1747-1346.2012.00395.x.

Shapiro, Fred R. 2006. The Yale Book of Quotations. Yale University Press.

Tedin, Kent L. 1974. "The Influence of Parents on the Political Attitudes of Adolescents." The American Political Science Review 68 (4): 1579-92. doi:10.2307/1959943. 
Table 1: Summary Statistics (2008 - McCain vs. Obama)

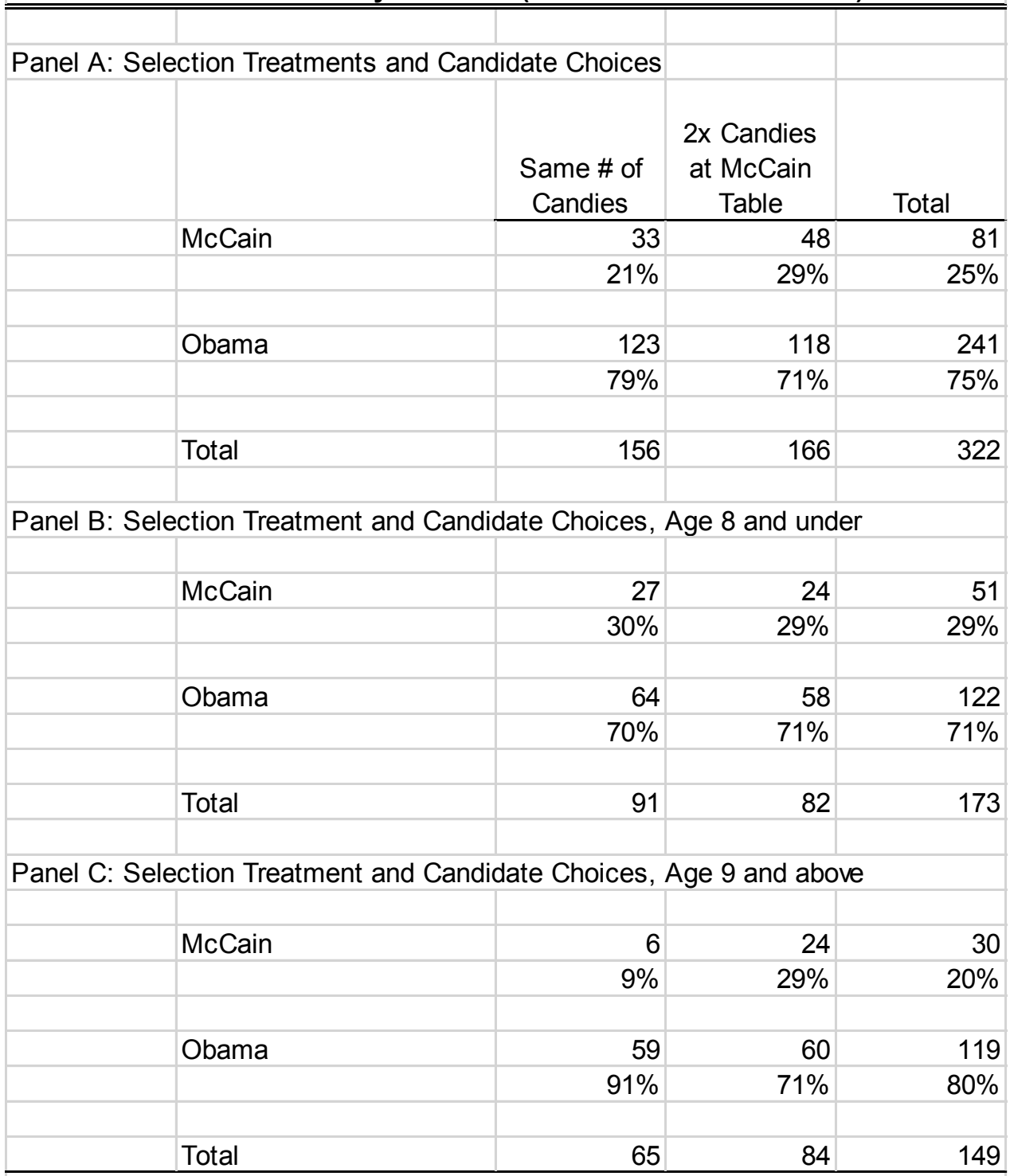

Note 1: P-values for the t-test of equality of proportion choosing Obama in Column 1 versus Column 2 is [0.044], [0.797], and [0.001] for Panels A, B and C, respectively. Analysis similar to Panel $\mathrm{B}$ and Panel $\mathrm{C}$ but for males and females yielded no significant heterogeneity. 
Table 2: Sample Frame Description (2008)

\begin{tabular}{|r|r|r|r|}
\hline \hline Age & Frequency & Percent & $\begin{array}{c}\text { Cumulative } \\
\text { Percent }\end{array}$ \\
\hline 4-8 years & 173 & 52.11 & 52.11 \\
\hline 11-14 years & 75 & 22.59 & 74.70 \\
\hline Missing & 10 & 3.01 & 100.00 \\
\hline Total & 332 & 100.00 & \\
\hline & & & \\
\hline Time of evening & & & 11.80 \\
\hline 5.30pm-6.30pm & 38 & 11.80 & 60.56 \\
\hline 7.30pm -7.30pm & 157 & 48.76 & 100.00 \\
\hline Total & 322 & 100.00 & \\
\hline Tonder & & & \\
\hline Male & 158 & 49.07 & 49.07 \\
\hline Female & 164 & 50.93 & 100.00 \\
\hline & 322 & 100.00 & \\
\hline
\end{tabular}


Table 3: Summary Statistics (2012 - Romney vs. Obama)

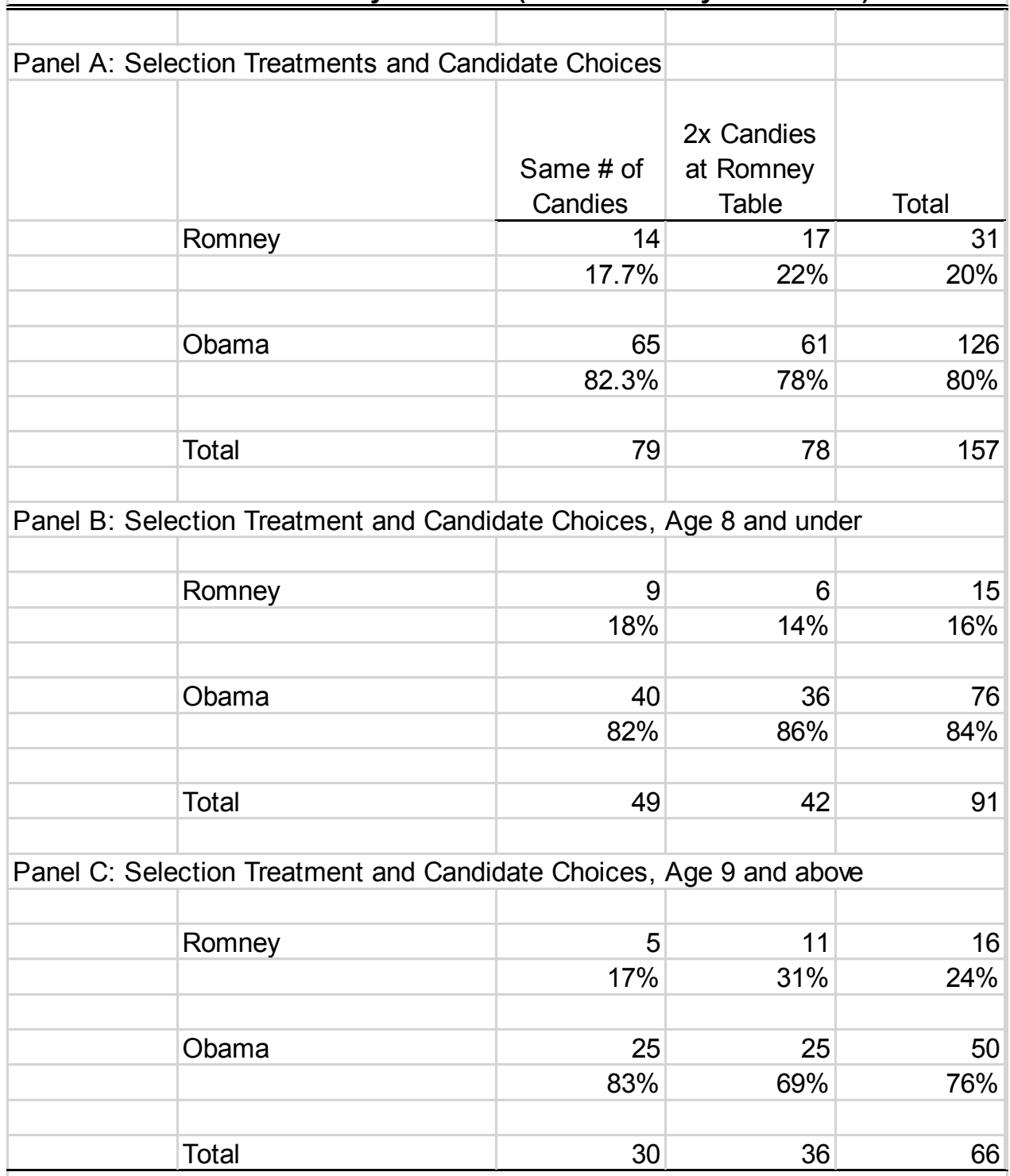

Note 1: P-values for the t-test of equality of proportion choosing Obama in Column 1 versus Column 2 is [0.500], [0.603], and [0.165] for Panels A, B and C, respectively. Analysis similar to Panel $B$ and Panel $C$ but for males and females yielded no significant heterogeneity. 
Table 4: Sample Frame Description (2012)

\begin{tabular}{|r|r|r|r|}
\hline \hline Age & Frequency & Percent & $\begin{array}{c}\text { Cumulative } \\
\text { Percent }\end{array}$ \\
\hline 4-8 years & 91 & 57.96 & 57.96 \\
\hline $9-10$ years & 33 & 21.02 & 78.98 \\
\hline $11-13$ years & 33 & 21.02 & 100.00 \\
\hline Total & 157 & 100.00 & \\
\hline & & & \\
\hline Gender & & & \\
\hline Male & 76 & 48.41 & 48.41 \\
\hline Total & 157 & 100.00 & \\
\hline
\end{tabular}

